Tohoku J. Exp. Med., 2003, 199, 35-42

\title{
A Morphometric Study on the Humerus for Intramedullary Fixation
}

\author{
Fuat Akpinar, Atif Aydinlioğlu, ${ }^{1}$ Nihat Tosun, Ali Doğan, \\ İBrahim TuncAY and ÖZKAN ǗNAL ${ }^{2}$ \\ Departments of Orthopaedics and Traumatology, ${ }^{1}$ Anatomy, and ${ }^{2}$ Radiology, \\ Faculty of Medicine, Yiuzüncü Yıl University, Van, Turkey
}

\begin{abstract}
Akpinar, F., Aydinlioğlu, A., Tosun, N., DoĞan, A., Tuncay, İ. and Ǘnal, Ö. A Morphometric Study on the Humerus for Intramedullary Fixation. Tohoku J. Exp. Med., 2003, 199(1), 35-42 — In recent years, the popularity of intramedullary humeral nailing is on the rise in spite of its handicaps. There are many problems in intramedullary humeral stabilization because of the anatomic structure of the bone. We performed various methods and measurements to determine shape, length and diameter and curvature of the medullary canal of the humerus in 57 human dry cadaver bones. Anterior angulation with an average of $21 \mathrm{~cm}$ apart from greater tubercle was found at $1 / 3$ distal part. Mean degree of angulation was $9^{\circ}$ (max: 15, minutes: 5, S.D.: 2.84). Humerus bones with septal aperture (supratrochlear foramen) at the fossa coronoidea were observed to have very narrow medullary canal. The best point for nail insertion was found to be an area on the line from greater tubercle anteromedially to caput humeri. This study revealed that carefully evaluated structure of humeral medullary canal and various congenital constructions such as septal aperture, and correct selection of a nail with proper length and diameter are essential for successful nailing.

Humerus; morphometric measurement; entry point; intramedullary nail; septal aperture

(C) 2003 Tohoku University Medical Press
\end{abstract}

Intramedullary fixation of long bones has been increasingly preferred especially following traumatic injuries and pathologic fractures. Intramedullary nailing has many advantages. In recent years, advantages of intramedullary fixation encouraged development of such a system for the humerus. However, due to characteristic anatomical features of the humerus, reamed or unreamed, and locked or unlocked intramedullary fixation methods could not be extensively used, unreamed locked nails being slightly favoured. Thus, the popularity of intramedullary humeral nailing is on the rise in spite of its handicaps. Maintenance of anatomic alignment and proper rapid stabilization for traumatic or pathologic problems of humerus would benefit patient and orthopaedic surgeon alike.

Received April 25, 2002; revision accepted for publication January 27, 2003.

Address for reprints: Atıf Aydınlıŏllu, M.D., Ph.D., Tıp Fakültesi, Araştırma Hastanesi, Anatomi

Anabilim Dalı, Yüzüncü Yıl Üniversitesi, 65200, Van, Turkey.

e-mail: aatif48@hotmail.com 
Orthopaedic surgeons have agreed with each other that most humeral shaft fractures can be treated by conservative measurements successfully. Various nonsurgical treatment methods result in a higher incidence of union and fewer problems than open reduction and internal fixation (ORIF). When ORIF is indicated, although plate-screw osteosynthesis seems to be as a gold standard (Modabber and Jupiter 1998; McCormack et al. 2000), intramedullary fixation has more advantages than plate-screw fixation and other measures in some conditions such as segmental or pathologic fractures (Durbin et al. 1983; Crolla et al. 1993; Redmond et al. 1996; Schrats et al. 1998; Gaullier et al. 1999).

As technology has progressed in the last several years with improved instrumentation and better implants, the complications previously associated with the intramedullary nailing of the humerus may be minimized with a new technique. Most investigations on intramedullary nailing of the humerus show healing rates between 85\% and 95\% (Durbin et al. 1983; Ward and White 1989; Crolla et al. 1993; Brumback 1996). Yet, there are many problems in intramedullary humeral stabilization and frac- ture healing with ORIF because of the anatomic structure of the bone. Some of these problems are selection of correct patient, difficulties of careful preoperative planning, determination of the proper nail length and diameter and the point of insertion (Ochsner 1989). For this purpose, the present study investigated anatomical properties of the humerus in detail on dry adult cadaver bones. New informations for intramedullary fixation and anatomical properties of the humerus are reported in this paper.

\section{Materials AND MeTHODS}

We evaluated anatomical structure of the medullary canal of humerus on 57 dry adult cadaver bones (Figs. 1-6). For determination of the proper diameter and length of the nail, the entry point, and the stress points nonreaming procedure was applied.

\section{Anatomic and radiographic study}

The cadaver bones were code-numbered from 1 to 57 . In order to elucidate the relation between cortex and medulla and the structure of the medulla along the bone, 5 bones with same length (No: 7, 15, 16, 25, 38) were axially scanned with CT starting from $2 \mathrm{~cm}$ distal of

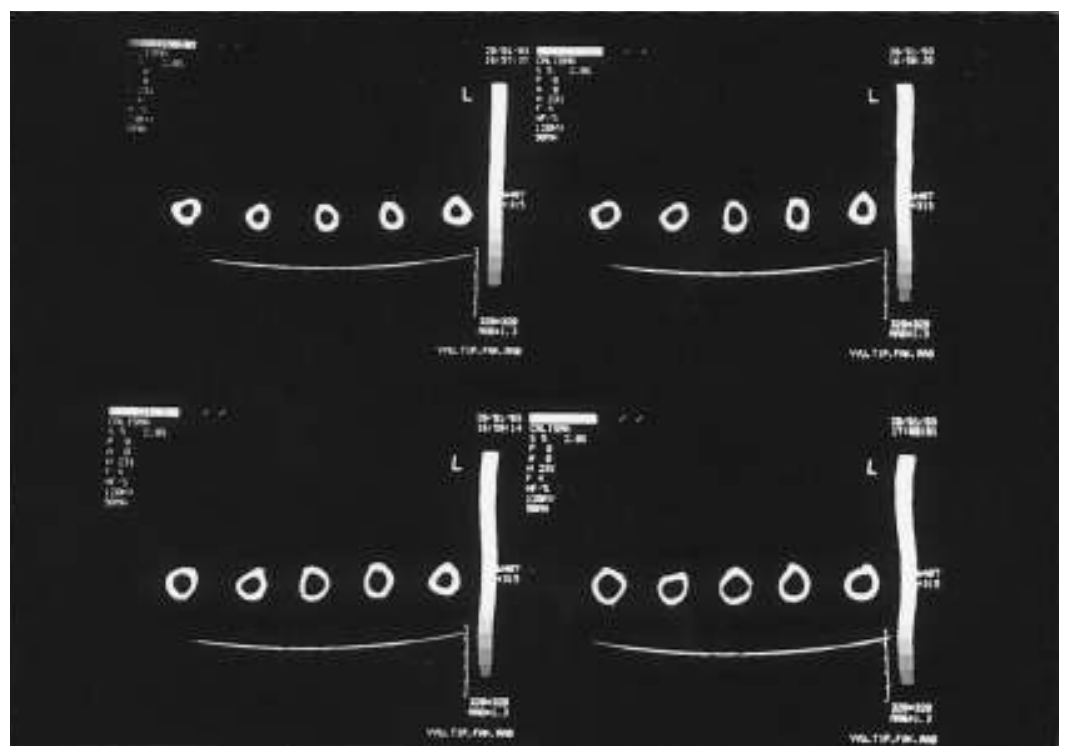

Fig. 1. Different diameter and shapes of the medullae on CT scans. 


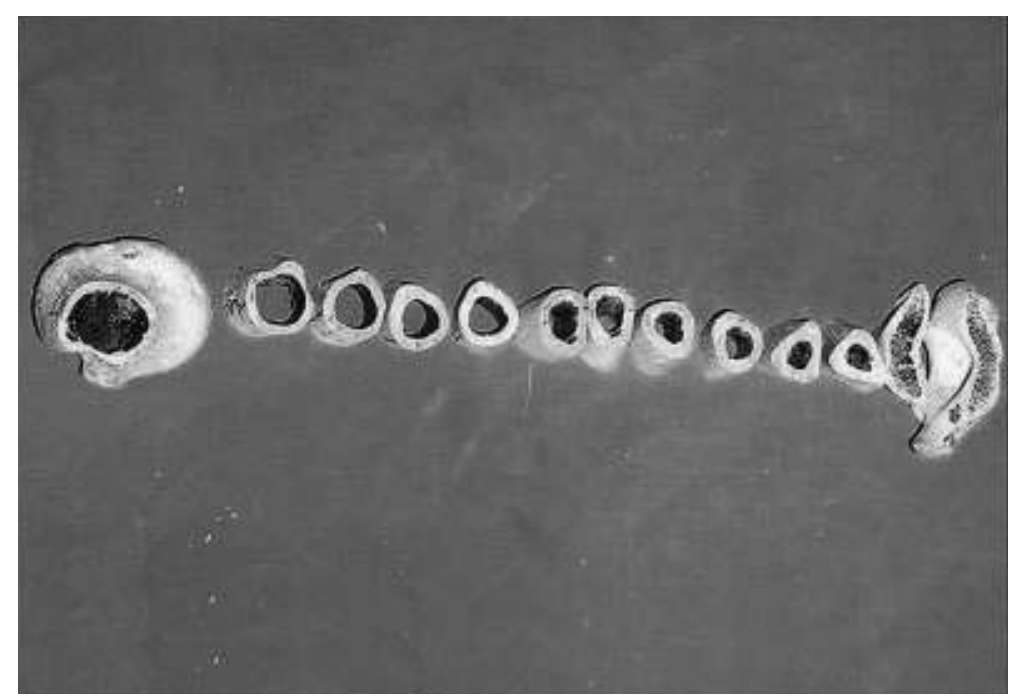

Fig. 2. Photograph showing increasing diameter of medullary canal from distal to proximal.

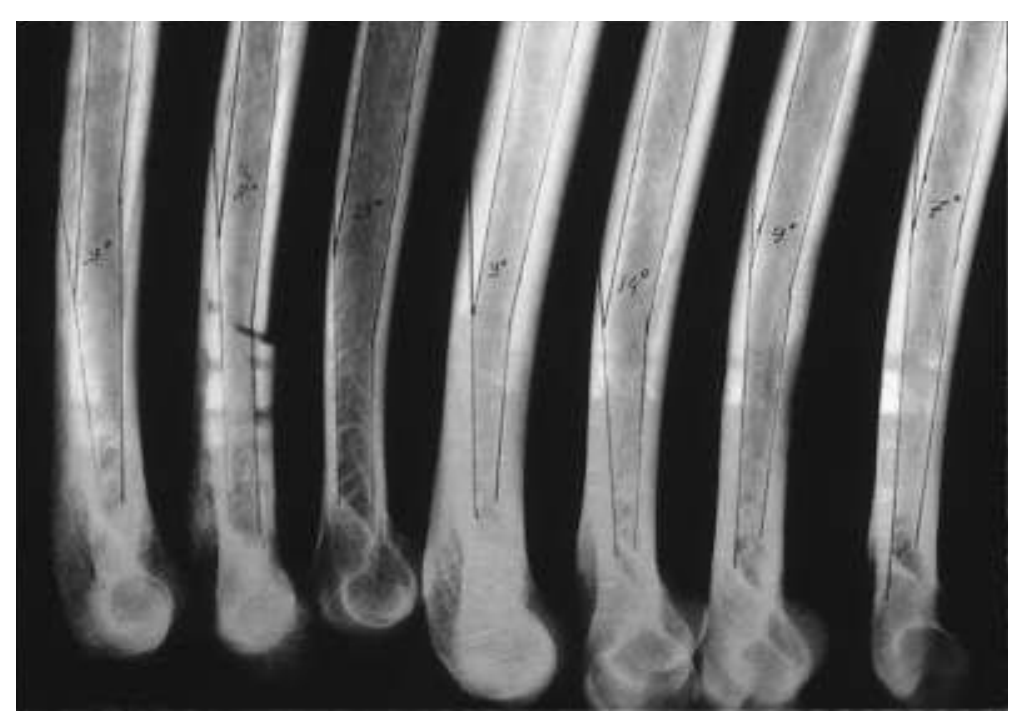

Fig. 3. Lat. radiological view showing anterior angulations.

greater tubercle to distally at $3 \mathrm{~cm}$ intervals (Fig. 1). In addition, one humerus (No:3) was cut with a saw from greater tubercle towards distal at $2 \mathrm{~cm}$ intervals. The pieces were placed perpendicularly for x-ray imaging to view their medullary canals (Fig. 2).

\section{Determination of angulation point and degree}

Anterior angulation site with reference to greater tubercle and its degree on the distal shaft were determined in lateral (Lat.) radiographies of No: 1-38. The anterior and posterior boundaries of the medullary canal were marked by longitudinal lines. The anterior angulations in $1 / 3$ distal part were measured by using protractor (Fig. 3).

Determination of the proper diameter and length of the nail

Anteroposterior (AP) and Lat. radiographies of bones No: 1-38 were taken from 1 meter distance in order to determine the proper diameter of the nail to be used prior to application. Then, 8-mm straight-round nails 


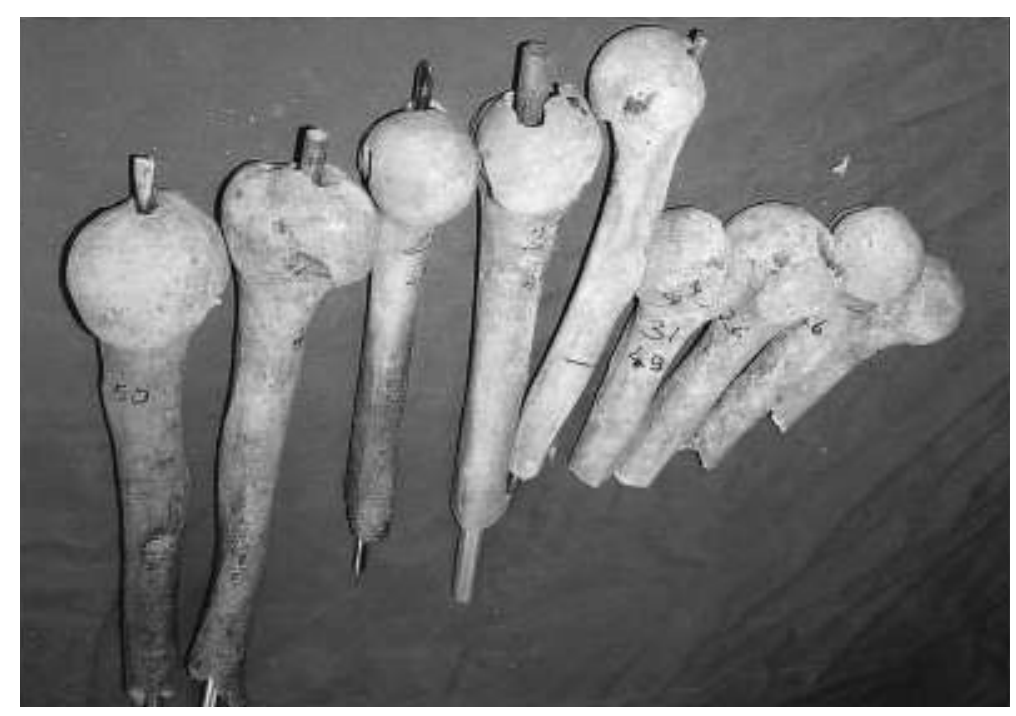

Fig. 4. On the bones distally broken, determination of entry point.

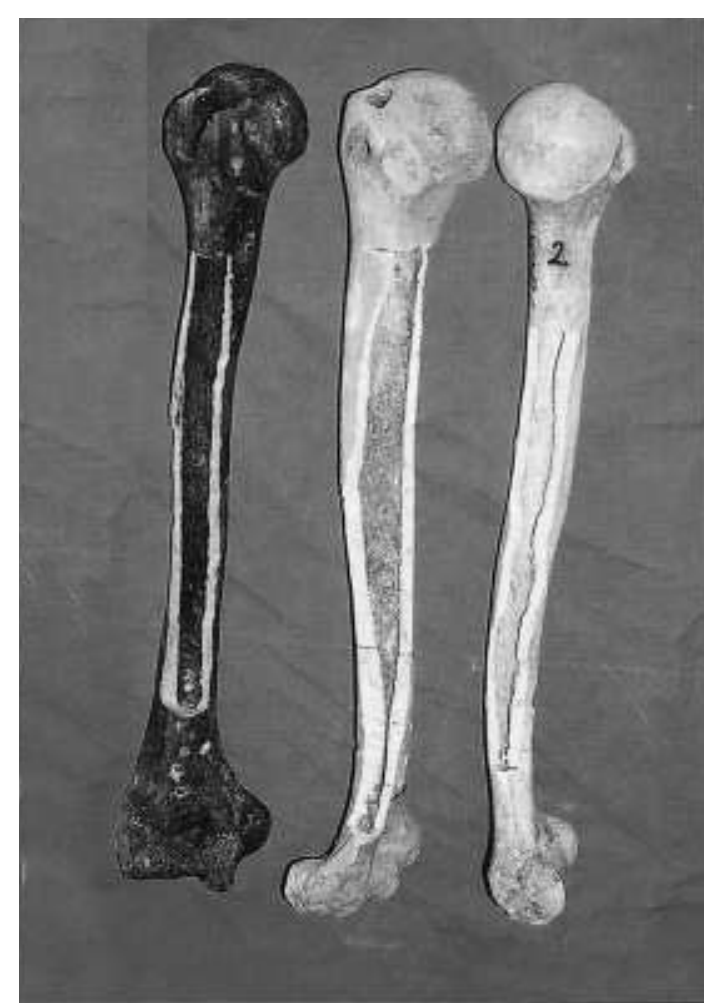

Fig. 5. Bones longitudinally resected for determination of stress points.

(Custom-made rods by Tasarımmed ${ }^{\circledR}$ Co., Istanbul, Turkey) were inserted into the bones to the most distal end and another set of radiographies was taken. From the x-ray's, the narrowest part of the humeral medulla was deter- mined, measured and compared with the diameter of $8 \mathrm{~mm}$ straight-round nails.

In order to determine the proper nail length, bones No: 1-38 were used. The nails with $8-\mathrm{mm}$ diameter which could reach to the 


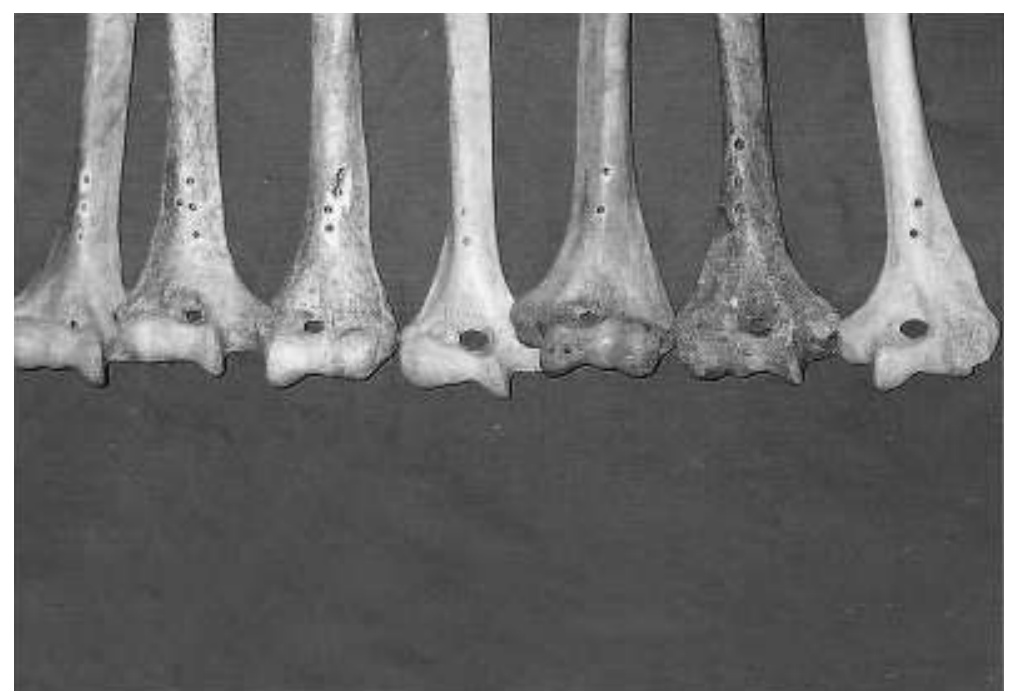

Fig. 6. Bones with distal septal aperture (supratrochlear foramen).

most distal end were inserted into the medulla. The lengths of the bones from the proximal articular surfaces to the distal articular surfaces were also measured. In order to determine the mean length between the tip of an inserted nail and fossa olecrani, the differences between the lengths of the bones and intramedullary placed nails were calculated and averaged.

\section{Determination of entry point}

In order to find out the best point for nail insertion (entry point), straight-round nails with a maximum diameter were retrogradely inserted through the medulla of 5 bones (No: 53-57) which had been distally broken at the different points and pushed out from the proximal end. The positions of exit points were determined (Fig. 4).

\section{Determination of stress point}

In order to determine the points and areas on which the nail exerts stress No: 2, 7, and 9 were used. For this purpose, longitudinal resections were made on as: anteromedial, anterolateral and posterior surfaces while the nails were inside the medulla. The contact points, areas and position of distal tip of the nails were determined (Fig. 5).

\section{RESULTS}

Of the 57 dry adult cadaver bones, 26 (46\%) were left and 31 (54\%) were right. The longest bone was $33 \mathrm{~cm}$ in length, the shortest $26 \mathrm{~cm}$ and the mean length of the 38 complete bone was 29 . $3 \mathrm{~cm}$ (S.D.: 2.4). Five bones were broken distally and 14 proximally. Table 1 summaries the results of the present study.

\section{Angulation point and degree}

Most of them had considerable anterior angulation at $1 / 3$ distal part. The point of anterior angulation was average of $21 \mathrm{~cm}$ ( $\max$ : 27, minutes: 17, S.D.: 3.9) apart from greater tubercle and mean degree of angulation was $9^{\circ}$ (max: 15, minutes: 5, S.D.: 2.8). Slight anterior angulation was observed at the midpoint between medial and proximal one third in all bones, but some had extreme anterolateral angulation at this point. Although their medullary diameters were wider than the nails, we had difficulty in insertion and the installed intramedullary nails lengths were very short.

\section{Anatomic and radiographic observations}

Diameter and shapes of the medullae were observed to be different on the axial CT scans 
TABle 1. Parameters used in our study and results (values in $\mathrm{cm}$ )

\begin{tabular}{lcrcc}
\hline & Max & Min & Mean & s.D. \\
\hline Bone length (No: 38) & 33 & 26 & 29.3 & 2.0 \\
Length of installed nail with $8 \mathrm{~mm}$ & 26.5 & 5 & 18.9 & 4.6 \\
Lat. x-ray diameter & 8 & 4 & 6.9 & 1.2 \\
AP x-ray diameter & 10 & 5 & 7.3 & 1.3 \\
Distal anterior angulation point & 27 & 17 & 21 & 3.9 \\
Distal anterior angulation (degree) & 15 & 5 & 9.1 & 2.8 \\
Distance between distal tip of installed 8 mm nail and fossa olecrani & 18 & 2 & 6.9 & 3.7 \\
\hline
\end{tabular}

taken at 3-cm intervals from five bones. Additionally, changing medullary diameter and shapes were observed on the X-ray of the sectional humerus No: 3 cut at 2-cm intervals. Both axial CT scans and x-rays revealed an increase in diameter of medullary canal of the humeri from distal to proximal end (Figs. 1 and 2). The narrowest and widest diameters were 4 and $8 \mathrm{~mm}$ respectively on Lat. radiographies while they were 5 and $10 \mathrm{~mm}$ on $\mathrm{AP}$ ones at the narrowest segments. On the AP and Lat. radiographies, the medullary diameters at the narrowest segments were found to be equal in 9 (24\%), while in $29(76 \%)$ AP diameters were greater than Lat. ones.

\section{Relationship of medullary canal to septal aper- ture}

There was a septal aperture (supratrochlear foramen) in 9 of 52 bones (17\%) at the fossa coronoidea and two of these had extreme anterolateral bowing at the $2 / 3$ proximal part. Between 1/3 middle and distal junction, extreme anterolateral compressed surface was in three of these bones. Also one right and one left humerus with septal aperture and equal characteristically structures which were thought to belong the same person had very narrow medullary canal through which a 4 -mm diameter Steinman pin could be inserted. These apertures's shapes and sizes of diameter were different (Fig. 6).

\section{Optimal entry point}

The best point for nail insertion (entry point) appears to be a point anteromedial greater tubercle towards caput humeri. In some instances, articular surface of the caput was destructed by 2-7 mm (mean $3.5 \mathrm{~mm}$ ) at the nail entry point (Fig. 4).

\section{Proper nail diameter and length}

On the AP and Lat. radiographies, mean length of straight-round nails with $8 \mathrm{~mm}$ diameter was $21.7 \mathrm{~cm}$. The average distance between the tips of the inserted straight-round nails diameter with 8-mm and the fossa olecrani was $6.9 \mathrm{~cm}$ (2-10, S.D.: 3.69). The nail tips were located medially in all bones.

\section{Stress points}

Our investigations revealed that the stress points/areas on the intramedullary straightround nail lie anteromedially in the caput, laterally in the middle $1 / 3$, posterolaterally in the area between middle and distal $1 / 3$ and posteromedially in the distal $1 / 3$ of the bone.

\section{DISCUSSION}

The humerus, the longest and largest bone in the arm, has expanded ends and a shaft. The shaft, in its proximal half almost cylindrical, is distally prismatic and anteroposteriorly compressed. Its three surfaces (anterolateral, anteromedial, posterior) and borders (anterior, lateral, medial) are not equally obvious 
(Williams et al. 1989). The endosteal canal of the humerus is straight and funnel shaped. Distally, the endosteal canal narrows just below the midshaft level into a small-diameter, closedended tube. The isthmus occurs at the junction of the middle and distal thirds of the shaft, and extends distally with a fairly constant diameter until the obliteration of the endosteal canal in the supracondylar region is reached (Brumback 1996).

Our study revealed that three important aspects should be especially taken care at the anatomical structure of the humerus in preoperative planning. The first one is humeral anterior angulation located at $1 / 3$ distal part which was average of $21 \mathrm{~cm}$ apart from greater tubercle and angulation degree was $9^{\circ}$. The second is extreme anterolateral angulation at the proximal two thirds. In the presence of such conditions, the medullary diameter are wider than nails, nails insertion will be very difficult. The third aspect is humeral variation such as septal aperture concomitant with narrow medullary humeral canal. Patient with narrow humeral medullary canal and extreme angulation should be carefully evaluated. Although no remarkable data is present in the previous reports, to our opinion, these conditions are very important for intramedullary fixation in preoperative planning.

There is some suggestion in the literature about which radiographies should be considered while determining the proper straight nail diameter preoperatively. The smallest of the AP and Lat. views measurements were preferred to determine the competency of the medullary canal which implies the narrowest part of humeral medullary canal (Riemer 1996). Interlocking nails have been designed with even smaller diameters than those seen in the tibia, because the humeral canal generally may have an endosteal diameter of 6 or $7 \mathrm{~mm}$ (Brumback 1996). It is obvious from the axial CT scans as well as from the direct radiographies of cut sections that medullary canal of humerus is of varying size and shape at different segments enlarging from distal to proximal.

In our study, the diameters determined at the narrowest segments $(5-10 \mathrm{~mm}$ on $\mathrm{AP}$ and 4 $-8 \mathrm{~mm}$ on Lat. radiographies) agree with the literature. Although AP measurements were equal to lateral ones in 9 of the bones, they were found to be different in 29 being $\mathrm{AP}>$ Lat. Furthermore when it is considered that humerus has an anterolateral angulation in the $1 / 3$ proximal and an anterior angulation in the $1 / 3$ distal, it appears quite difficult to choose preoperatively the proper nail that could be easily inserted. Regarding shape and diameter of humerus we suggest conical shape nail enlarging from distal to proximal end. Such a nail generally ensures full endosteal cortical contact and can be inserted more distally than straightround nail that most surgeons would prefer (Ochsner et al. 1989; Crenshaw 1998).

The entry point on the proximal humerus should be correctly positioned. In the literature, there are nearly similar suggestions about this (Brumback 1996; Riemer 1996; Crenshaw 1998; Kropfl et al. 2000). In our study, however, we showed that nails with largest diameter that were retrogradely inserted from the cut distal ends came out at a point anteromedial to the greater tubercle towards caput humeri. In this condition articular surface of caput was only destructed by 2-7 $\mathrm{mm}$ (mean $3.5 \mathrm{~mm}$ ) at the nail entry point. When the entry point was shifted away from this area, even if the diameter was reduced, it was hardly possible for the nail to pass through the medulla distally. If this condition were insisted either collum chirurgicum or medial cortex might be fractured.

According to the literature, the proper nail length can be calculated by subtracting $5 \mathrm{~cm}$ from fixed humerus length (the distance between the tip of the greater tubercle and the distal articular surface) and the nail should end approximately 1 to $2 \mathrm{~cm}$ proximal to the olecranon fossa (Crenshaw 1998). However, our study indicated that this value, $5 \mathrm{~cm}$, is not 
consistent, but varies from $5 \mathrm{~cm}$ to $21 \mathrm{~cm}$ which are calculated by adding the length of the condylar area $(\sim 3 \mathrm{~cm})$ to the installed nail lengths (Table 1).

We failed to find any comparable study relating to the stress points in the literature. They will probably be the most heavily points effected during reaming procedure.

In conclusion, the present study showed that considering possible extreme anterior angulation at the distal humerus, nails with various lengths should be available preoperatively. This will prevent the possibility of damage to the distal fragment or nail incarceration.

\section{References}

Brumback, R.J. (1996) The rationales of interlocking nailing of the femur, tibia and humerus. Clin. Orthop., 324, 292-320.

Crenshaw, A.H., Jr. (1998) Fractures of Shoulder Girdle, Arm and Forearm. In: Campbell's Operative Orthopaedics, edited by S.T. Canale, Mosby, Missouri, pp. 2298-2309.

Crolla, R.M.P.H., de Vries, L.S. \& Clevers, G.J. (1993) Locked intramedullary nailing of humeral fractures. Injury, 24, 403-406.

Durbin, R.A., Gottesman, M.J. \& Saunders, K.C. (1983) Hackethal stacked nailing of humeral shaft fractures. Experience with 30 patients. Clin. Orthop., 179, 168-174.

Gaullier, O., Rebai, L., Dunaud, J.L., Moughabghab, M. \& Benaissa, S. (1999) Treatment of fresh humeral diaphysis fractures by Seidel intramedullary locked nailing. A study of initial cases after 2.5 years with rotator cuff evaluation. Rev. Chir. Orthop. Reparatrice Appar. Mot., 85, 349-361.
Kropfl, A., Naglik, H., Niederwieser, B. \& Hertz, H. (2000) Unreamed antegrade humeral interlocking nailing. Unfallchirurg., 103, 348-354.

McCormack, R.G., Brien, D., Buckley, R.E., McKee, M.D., Powell, J. \& Schemitsch, E.H. (2000) Fixation of fractures of the shaft of the humerus by dynamic compression plate or intramedullary nail. A prospective, randomised trial. J. Bone Joint Surg., 82B, 336339.

Modabber, M.R. \& Jupiter, J.B. (1998) Operative management of diaphyseal fractures of the humerus. Plate versus nail. Clin. Orthop., 347, 93-104.

Ochsner, P.E., Baumgart, F. \& Kohler, G. (1989) Heat-induced segmental necrosis after reaming of one humeral and two tibial fractures with a narrow medullary canal. Injury, 29, Suppl., 2, B1-B10.

Redmond, B.J., Biermann, S., Blaiser, R.B. \& Michigan, A.A. (1996) Interlocking intramedullary nailing of pathological fractures of the shaft of the humerus. J. Bone Joint Surg., 78A, 891-896.

Riemer, B.L. (1996) Intramedullary nailing of the humerus. In: The Science and Practice of Intramedullary Nailing, edited by B.D. Browner, Williams \& Wilkins, Philadelphia, pp. 241-265.

Schratz, W., Worsdorfer, O., Klockner, C., Gotze, C. (1998) Treatment of humeral shaft fracture with intramedullary procedures (Siedel nail, Marchetti-Vicenzi nail, Prevot pins). Unfallchirurg., 101, 12-17.

Ward, E.F. \& White, J.L. (1989) Interlocked intramedullary nailing of the humerus. Orthopedics, 12, 135-141.

Williams, P.L., Warmick, R., Dyson, M. \& Bannister, L.H. (1989) Gray's Anatomy, 37th ed., Churchill Livingstone, London, pp. 406-410. 